\title{
The Role Of External Review Agents In Information Systems Disaster Recovery Planning (DRP) In Community-Based Institutions
}

Felix F. Dreher, (E-mail: ffdreher@mail.pittstate.edu), Pittsburg State University (Kansas) John B. English, (E-mail: jbenglis@mail.pittstate.edu), Pittsburg State University (Kansas)

\begin{abstract}
A survey of credit unions, school districts, and hospitals provided a sample of computer users subject to external financial, regulatory, and accreditation reviews in which DRP ${ }^{l}$ is considered an essential part of the process. This study examined the perceptions of top-level managers in these three institutions toward the role of external review agents in increasing the awareness of management to their responsibilities in DRP. The findings indicate that the managers surveyed perceive the influence of external DRP review agents to be relatively unimportant. This attitude represents a stark deviation from the recommendations provided in current DRP research literature.
\end{abstract}

\section{Introduction}

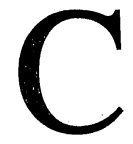

ommunity-based institutions are traditionally found in education, healthcare, and similar service-based programs; such as financial, legal, and social services. The introduction of computer technology has allowed these organizations to provide more efficient and timely services for their clients, better operational controls, and improved management reporting tools. However, the rapid growth in dependence upon computer technology requires consideration of how an institution would cope with a rare, but often major, disruption that im-

Readers with comments or questions are encouraged to contact the authors via e-mail. pacts upon its information systems resources.

These disasters may be natural; such as fires, floods, lightning, earthquakes, hurricanes, or tornadoes. They may also be man-made; such as explosions, sabotage, and theft. For an organization that lacks a plan, the failure of a communications system, central processing unit, or even a disk drive, could constitute a threat to the viability of the institution. Examples of various types of business disasters and actions taken in response to them can be found in Appleby (1996), Clolery (1993), Dash (1997), Dwyer, et. al., (1993), Editor (1994), Kahan (1994), Klien (1992), Lenckus (1992), Powell (1990), and 
Romei, et. al., (1995).

As McManus (1988) points out, every employee must become actively involved in DRP, but top-level management is ultimately responsible for the success and survival of the firm. They alone can assess those activities most crucial to the firm. For this study, therefore, toplevel managers in three distinct classes of institutions were surveyed: federally insured credit unions, school districts, and hospitals.

These organizations share many common traits. They are community-based with limited outreach programs or branches, are often notfor-profit operations, and have an elected or voluntary Board of Directors that oversee the financial health of the institution. All of these are also experiencing a rapid infusion of information technology, including personal computers, multiuser systems, local-area networks, and wide-area networks. They also employ critical application programs directly related to day-to-day operations.

Credit unions are rapidly becoming dependent on wire transfers of payrolls and investments, automated teller machines to provide customers access to their accounts, access to credit reporting services to assist in loan decisions, and daily analysis of investment portfolios to manage investments in treasury notes or certificates of deposit.

Hospitals are moving toward on-line medical records, automated laboratory procedures, computer-based imaging systems, and network-based tele-medicine. They are also installing the traditional purchasing, billing, scheduling, and personnel systems. School districts, on the other hand, are now using computers in individual classrooms, gaining access to the Internet for classroom and research support, and employing interactive distance learning facilities to provide educational experiences to small groups that are geographically dispersed.

Another characteristic common to these establishments is the existence of external review agencies that are charged with their oversight. Credit unions are subject to review by both federal and state examiners, school districts by the state's Board of Education and regional accreditation agencies, and hospitals are required to submit materials related to both operational and financial matters to a Board of Healing Arts. Additionally, many hospitals choose to seek accreditation from the Joint Commission for Accreditation of Healthcare Organizations (JCOACH).

\section{Literature Review}

Researchers have noted that the continuing growth in dependence upon rapidly changing computer technology raises concerns about an institution's ability to respond to a disaster of any kind. Appleby (1996) states that "traditional backups like batteries, generators and manual operations are not obsolete, but pale in comparison to the high-tech disaster recovery needs of today's businesses." An ATM application for credit unions requires access to a national network service via dedicated communications lines supported by on-line premise equipment. Hospital nursing stations routinely employ terminals or workstations to examine or update patient records and to order tests, special diets, or pharmaceutical items. In school districts, distance learning facilities involve codecs to compress video and audio signals and to interface to dedicated communication facilities at several sites to allow a two-way interaction between students and teachers.

Much of the hardware and software required to prepare for a disaster in these areas is proprietary and can be obtained from several different vendors. Muckian (1994) discusses DRP software and a planning handbook available for credit unions. Classe (1991) provides a list of selected firms providing disaster recovery services. Cerullo, et. al., (1994) also provides a listing of agencies that can aid in identifying potential disruptions, estimating losses, and developing a comprehensive disaster plan.

Dash (1997), Klein 1992), Lenckus 
(1993), Muckian (1994), and Romei, et. al., (1995) all relate incidents of various companies involved in disasters and the effect of DRP on the outcome of these encounters. Stone and Frick (1992), on the other hand, relate the results of a mock-disaster test on a real-world company's disaster plan. Lastly, Vijayaraman and Ramakrishna (1993) present the results of a survey concerning the types, costs, and occurrences of different types of disasters effecting various firms.

Luecke and Hoopingarner (1993), writing in regard to healthcare management, also describe the expanding burden of DRP resulting from the burgeoning use of information technology in an institutional setting. They note that personnel, particularly those who have recently completed their education using automated systems, have grown accustomed to technologybased methods and may lack experience in dealing with manual methods that were the mainstay of earlier times.

Lamond (1990) and Poker (1989) point out that the need for a critical systems inventory is considered an essential part of preparing a disaster plan. Due to the system wide impact of technology, this inventory requires input from all levels and all personnel of the organization. Hankins and Barnett (1991), however, relate that disaster planning must begin with a commitment from the Board of Directors and spells out the board's role in the process.

Burch (1989), Gauthier and Buchanan (1989), Haight and Byers (1991), Hurd (1994), Macoy (1992), Rosenthal and Sheiniuk (1993), Stone and Frick (1992), and Wong, et. al., (1994) provide consultation and discuss detailed steps for risk assessment and development and implementation of a disaster plan. These authors also frequently stress the critical role of the Board of Directors, CEO, and financial management team. Luecke and Hoopingarner (1993) even list four major DRP tasks that are expanding the involvement of the financial management team and are related to the current study:
1. Applying risk analysis techniques to quantify the institution's exposure in the event of a significant disruption of automated systems.

2. Studying recent internal and external auditing reports to identify possible concerns with the organization's ability to function in the absence of automated systems and the ability to recover from such a disruption.

3. Determining whether outside consulting services will be necessary or advisable to address critical planning areas, or if the process can be completely internalized.

4. Reviewing the plan with the management team to gain its approval. The plan should be submitted for examination by the Board of directors.

Burch (1989) states that internal auditors have a professional and moral responsibility to ensure a disaster plan is in place, fully tested, and up-to-date. He also suggests four components of good DRP and the steps to employ in plan development, testing, and maintenance. Macoy (1992), Negròn (1992), Lamond (1990) and Morris (1992) point out the importance of external reviewing agencies in DRP.

Wesselingh (1989), writing for financial institutions, recognizes the need for standards of care and the involvement of the Board of Directors in an annual review of disaster plans. McManus (1988) and Phelps (1986) assert the responsibility of top-management in DRP. Wong, et. al., (1994), also offers suggestions for top-level and information systems managers to employ in DRP.

Luecke and Hoopingarner (1993) summarize DRP responsibilities stating that, "The business continuity plan is an institution's insurance policy assuring on-going operations, key data recovery, and uninterruptable cashflow Business continuity planning is best tackled by a task force." They also state, however, that the Board of Directors, top-level management, and reviewing agencies remain responsible for insuring the best possible plan is developed and tested. 
Appleby (1996) states that when information flow stops in a hospital not just profits, but the life and death of patients may well be jeopardized. He also notes that DRP is a requirement for JCAHO accreditation and discusses the role of external firms that can provide "hot-site" and consulting services. Kahan (1994) also provides valuable information on "hot sites."

Perry (1990) discusses the role of a DRP team in regards to a school catastrophe and notes computer services as an area of special concern. In the context of an educational, rather than financial, arena, the Illinois School Library Media Association Handbook (1994) on DRP discusses the special case of protection for library holdings. Kahn (1994) also provides information concerning library media recovery and includes problems related to protecting computer software.

Clolery (1993) points out that DRP is probably even more important for the sole practitioner than it is for a larger firm, since the smaller organization doesn't have a staff to rely on in a crisis. He also provides a seven step process and a checklist to follow in DRP. Cruden (1996) points out that over $90 \%$ of personal computer (PC) users do not backup their data at all. He relates that home PC users, small-tomedium sized businesses, and those in client/server environments face the greatest risk of losing historically significant information, because they fail to provide adequate backup procedures. Klien (1992) supports these findings concerning small-to-medium sized businesses.

Regardless of these research findings, Muckian (1994\} states that according to Doug Verner, the Director of the National Credit Union Administration (NCUA) Office of Technology and Information Services, reviewers expect credit unions to have a plan - but few external examiners spend much time reviewing plans. Additionally, Cerullo and McDuffie (1994) present results from a survey of 71 Charleston, SC companies following Hurricane Hugo. The results show that out of 41 usable returns $56 \%$ of the firms had no computer contingency plans. As late as this year, Dash (1997) reports that an ICR survey group study indicated that only $62 \%$ of the information systems respondents even had a disaster recovery plan. Articles by Hurd (1994), Dwyer (1993), Krezmein (1993), Lenckus (1993), and Haight and Byers (1991) all reflect this same lack of preparedness in both small and larger businesses. Yet, Hankins (1991) points out that the failure to safeguard information assets can subject the organization \& its management to liabilities \& penalties under the Foreign Corrupt Practices Act of 1977.

\section{Methodology}

An initial and follow-up survey of 319 federally insured credit unions in seven midwestern states resulted in 85 usable responses. The characteristics of, and partial results from, this survey were reported by Dreher and English (1996). The same survey was then sent to 304 superintendents of school districts and 142 hospital directors in Kansas. Along with a followup, these surveys resulted in 102 and 35 usable responses respectively.

The survey was designed to examine the attitude of the CEOs of these institution's relative to the: (a.) role and importance of computerbased (automated) systems, (b.) in daily operations, (c.) allocation of responsibilities for DRP, (d.) role and impact of external review agents (such as auditors, (e.) regulatory and accrediting groups, and consultants) on each of, and (f.) the above institution's DRP processes.

While the scope of this survey was geographically limited to a single state for two of the groups, the authors believe the exposure to potential disasters is reasonably high and uniform within the sampled population. Unfortunately, Kansas represents an area that is exposed to a wide variety of disasters; suffering damages due to tornadoes, flooding, hail, strong thunderstorms, fires, and even earthquakes.

A number of the surveyed organizations are relatively small and located in rural areas or 
smaller towns. These firms, however, are equally likely to suffer from disasters as those in large metropolitan areas, and have fewer resources available to cope with the disaster. The need to provide an adequate plan that accounts for limited resources and the lack of nearby services (such as "hot sites," computer repair centers, and communications support) imposes an even greater burden than that experienced by firms in less remote areas. The institutions surveyed should not, therefore, be unfamiliar with the DRP process.

\section{Research Results}

Characterizing the responding establishments revealed that the relative sizes varied widely, but on the average most of them would meet the guidelines for a small business. Table 1 presents the responses to selected demographic questions for all three groups. Please note that $\mathrm{SE}$ is the standard error involved in the measurement.

As can be seen in Table 1, hospitals, on the average, have more employees, managers, and information systems personnel than the other groups. The largest had 6,000 employees and 98 managers compared to the largest school district, which reported 1,000 employees and 80 managers. The largest credit union, on the other hand, reported only 166 employees and 50 managers. Since all the groups reported an average of slightly more than one information systems manager, it was expected that the financial management team would be heavily involved in the DRP process. As Table 2 reveals, the actual assignment of overall DRP responsibilities supported this expectation.

Table 2 indicates similar DRP responsibility assignments among the different types of institutions. Indeed, a Chi-square contingency test at the $90 \%$ significance level did not support a hypothesis of independence in assignments.

\section{The Role of External Review Agents}

The survey also required respondents to rate a wide variety of statements using a Likerttype scale where 1 represented "strongly disagree," 2 “disagree"” 3 "Neutral," 4 "agree," and 5 "strongly agree." Selected statements relevant to external review agents are presented in the left-hand column of Table 3 . The responses are shown in columns two through four. Please note again that $\mathrm{SE}$ is the standard error involved in the measurement.

Examining the number of "agree" or "strongly agree" answers to statement one in Table 3 revealed a $97.4 \%$ response for credit unions, $85.3 \%$ for hospitals, and $96.6 \%$ for school districts. Clearly top-level managers in this sample perceive computer-based systems to be of extreme importance. Examining the remaining statements, however, discloses a much less positive result. Only the credit union response to statement 5 even approaches agreement. The credit union reply to statement 3 is the only other result exceeding neutrality. All the remaining responses are on the "disagree" side of the rating scale.

Summarizing, credit union management doesn't perceive that external review agents examine their disaster plans, or at least not thoroughly. Yet, Table 3 also reveals that these managers don't seek the professional advice of outside consultants either. They do, however, perceive a greater awareness in examiners due to recent disasters. These perceptions appear to be in stark contrast to the available literature, which extols the moral and professional responsibilities of external review agents in the DRP process.

Even though hospitals and school districts involve more hard resources and people than credit unions, management perceptions in this area are no better than those of credit union managers. There is little requirement for federal or state examination of either establishment to ensure a readiness to deal with catastrophes, nor do they seek professional consulting advise in DRP. These two groups, therefore, do not even perceive an increase in awareness due to recent disasters. 


\begin{tabular}{|c|c|c|c|c|c|c|}
\hline \multicolumn{7}{|c|}{$\begin{array}{c}\text { Table 1: } \\
\text { Institutional Demographics }\end{array}$} \\
\hline & \multicolumn{2}{|c|}{ Credit Unions } & \multicolumn{2}{|c|}{ Hospitals } & \multicolumn{2}{|c|}{ School Districts } \\
\hline & Mean & $\underline{\mathrm{SE}}$ & Mean & $\underline{S E}$ & Mean & $\underline{\mathrm{SE}}$ \\
\hline Employees & 26.8 & 4.00 & 499.1 & 203.00 & 173.0 & 19.80 \\
\hline Managers/Officers & 5.2 & .76 & 10.6 & 3.50 & 6.9 & 1.10 \\
\hline IS Managers & 1.2 & .14 & 1.5 & .44 & 1.1 & .13 \\
\hline IS Programmers & 0.2 & .12 & 2.3 & 1.43 & 0.3 & .08 \\
\hline Others in IS & 1.6 & .12 & 3.4 & 1.10 & 1.6 & .12 \\
\hline Total IS Staff & 3.0 & & 7.2 & & 3.0 & \\
\hline
\end{tabular}

Table 2:

Actual Assignment of Overall DRP Responsibility

IS Director

Financial Officer

Several Officers

Outside Agent

Several Team Members

\begin{tabular}{ccc} 
Credit Unions & Hospitals & School Districts \\
\hline 11 & 1 & 18 \\
22 & 3 & 13 \\
31 & 10 & 24 \\
1 & 2 & 2 \\
17 & 16 & 33
\end{tabular}

Table 3:

Perceptions of the Role of External Review Agents in DRP

\begin{tabular}{|c|c|c|c|c|c|c|}
\hline \multirow[t]{2}{*}{ Statement } & \multicolumn{2}{|c|}{$\begin{array}{l}\text { Credit } \\
\text { Unions }\end{array}$} & \multicolumn{2}{|c|}{ Hospitals } & \multicolumn{2}{|c|}{$\begin{array}{l}\text { School } \\
\text { Districts }\end{array}$} \\
\hline & Mean & $\underline{\mathrm{SE}}$ & Mean & $\underline{S E}$ & Mean & $\underline{\mathrm{SE}}$ \\
\hline Computers are vital to operations. & 4.88 & .05 & 4.44 & .13 & 4.67 & .06 \\
\hline CPAs review our DRP. & 2.86 & .14 & 2.38 & .24 & 1.85 & .11 \\
\hline $\begin{array}{l}\text { Federal-State examiners review our } \\
\text { disaster plans. }\end{array}$ & 3.14 & .13 & 1.71 & .16 & 1.73 & .10 \\
\hline $\begin{array}{l}\text { Consultants advise management on disaster } \\
\text { planning. }\end{array}$ & 1.92 & .13 & 2.15 & .21 & 2.23 & .13 \\
\hline $\begin{array}{l}\text { Recent disasters have raised examiner awareness of } \\
\text { DRP. }\end{array}$ & 3.77 & .12 & 2.29 & .19 & 1.78 & .10 \\
\hline $\begin{array}{l}\text { The Board is active in cost-benefit analyses of our } \\
\text { disaster plans. }\end{array}$ & 2.45 & .14 & 2.09 & .21 & 2.03 & .12 \\
\hline
\end{tabular}

Unfortunately, Table 3 also reveals no difference in the responses of these three establishments to statement 6 . They do not perceive that the Board of Directors is actively involved in any cost-benefit analyses of DRP. When asked if management currently discussed DRP with their Board, however, $57.6 \%$ of the credit union CEOs stated they did so as a current practice. Hospital and school district responses to this same question disclosed that $47.1 \%$ of hospital managers did so as a current practice, but only $8.3 \%$ of school district superintendents discussed DRP with the Board.

\section{Conclusion}

While not a resounding endorsement for the role of external review agents in DRP, it ap- 
pears that reviews by federal-state examiners in credit unions reflect some increased awareness of the importance of DRP to the continued health and survival of the organization. Hospital and school officials, on the other hand, do not perceive the impact of federal or state reviews of DRP, nor do they perceive any value in external review of their DRP. In addition, none of the three groups perceive a significant role for consultants in DRP.

The literature suggests that hospitals seeking accreditation are subject to review in this area, but perhaps the majority of the hospitals surveyed in this study are not large enough to seek accreditation. Yet, researchers also suggest that smaller organizations require good DRP even more than the larger ones. Lastly, while the literature also stresses the need for an active role in DRP for managers at all levels, the involvement of the Board of Directors was marginal in credit unions and hospitals and almost nonexistent in school districts.

Considering the investment in highly technical resources, the number of consumers, and the monetary funds involved in the three institutions studied, external review of their disaster plans should be absolutely essential. Also, these reviews should be thorough in nature and pursued to ensure compliance on the part of managers at all levels. This study, however, did not find these requirements to be generally accepted nor practiced.

Some reasons for these results might include: 1) some managers may feel the level of risk does not justify the expense involved, 2) they may suffer from the "it can't happen to us" syndrome, 3) the task is just too big and time consuming, 4) lack of top management support, 5) lack of involvement on the part of all departments, 6) management attitudes (there are enough real daily problems to worry about hypothetical ones), and 7) the lack of resources, skilled personnel, expertise, and/or training.

Research efforts, however, are replete with examples, from all areas of business, of the tremendous losses involved in both natural and man-made calamities. Britt (1993) also reminds the business community that a disaster doesn't have to be a fire, flood, or tornado, it can be a simple computer problem or an error in a software program.

Our conclusion is that management in the three groups studied here does not value the role of external review agents in DRP as highly as the research literature suggests they should. Perhaps these reviewers are more concerned with other issues, not forceful enough, not thorough enough, or not visible enough, in their analyses. Another possible reason for this laxity may rest in where existing regulations and guidelines place the most emphasis. In a hospital, for instance, the emphasis appears to be on a community or internal disaster which involves a calamity that mandates the protection of patients and staff. The actual extent of the DRP emphasis placed on information systems in these circumstances is an unknown.

\section{Suggestions For Future Research}

While this paper deals with the role of external review agents in DRP, the authors see a need to examine the actual role of individuals within the institution. Distinguishing between the overall disaster plans and those directed toward the information systems component constitutes another area requiring future research.

A third research issue involves the differences in information system DRP models appropriate for each institution. A review of hospital information system components reveals patient admissions, insurance and billing, laboratory, patient medical and electronic imaging records. This implies that highly complex information systems DRP would be needed to deal with distributed resources and quite diverse system characteristics. School district disaster planning would probably not be quite as complex. Directors would have to deal with such things as classroom resources used for instruction and centralized financial and student records. 
Finally, research is needed to determine the role of the Board of Directors and their relationship to external review agents. The results of this study indicates that the Board of Directors assumes only a highly limited role in regards to DRP. Yet, the current research literature indicates that even a small calamity can have far reaching consequences for an institution with inadequate disaster plans.

\section{Footnote}

1. Business resumption planning or continuity planning are considered to be synonymous with disaster recovery planning.

\section{References}

1. Appleby, Chuck, "KA-BOOM!," Hospitals and Health Networks, pp. 31-34, August 20, 1996.

2. Britt, Phil, "Disaster Recovery: Automation Prompts Planning," Savings and Community Banking, p. 53, August, 1993.

3. Burch, John G., "Disaster Recovery Plan: A Moral and Professional Responsibility," Internal Auditor, pp. 43-46, June, 1989.

4. Cerullo, Michael J., R. Steve McDuffie, and L. Murphy Smith, "Planning for Disaster," The CPA Journal, pp. 34-38, June, 1994.

5. Classe, Alison, "Time to Think About the Unthinkable," Accountancy, pp. 111-113, July, 1991.

6. Clolery, Paul, "When disaster Strikes: Keep Your Practice Running," The Practical Accountant, pp. 24-28, May, 1993.

7. Cruden, Ken, "America's Data In Danger," Managing Office Technology, pp. 52-53, February, 1996.

8. Dash, Julekha, "Crash!," Software Magazine, pp. 48-51, February, 1997.

9. Dreher, Felix F. and John B. English, "Managerial Attitudes and Responsibilities for Disaster Recovery in Credit Unions: A Perspective," A paper presented at the 23rd Annual Meeting of the Southwestern Federation of Academic Disciplines, March, 1996.
10. Dwyer, Peggy D., Alan H. Friedberg, and Karen S. McKenzie, "The Importance of Continuity Planning," The National Public Accountant, pp. 28-39, June, 1993.

11. Editor, "Response to Mayday," The Banker, pp. 67-68, February, 1994.

12. Editor, School Library Media Center Disaster Response Plan Handbook, School Library Association, Canton, Illinois, 1994.

13. Haight, Nicholas and Randall Byers, "Disaster Recovery Planning: Don't Wait Until It Is Too Late," Journal of Systems Management, pp. 13-16, April, 1991.

14. Hankins, Robert D. and H. Wayne Barnett, "A Comprehensive Guide to Disaster Recovery Planning," The Bankers Magazine, pp. 41-47, May/June, 1991.

15. Hurd, Joanne E, "Do You Know Where the Briefcase Is? Reaching the Full Potential of Business Resumption Planning," Journal of Systems Management, pp. 1621, August, 1994.

16. Kahan, Stuart, "Hot Sites: The Solution When Business Interruption Is Fatal," The Practical Accountant, p. 58, July, 1994.

17. Kahn, Miriam, "Fires, Earthquakes, and Floods: How to Prepare Your Library and Staff," On-line, Vol. 18, No. 3, pp. 18-24, May, 1994.

18. Klein, Elizabeth, "If Disaster Strikes, Are You Ready?," Savings Institutions, pp. 2630, October, 1992.

19. Krezmien, Richard, "The disaster Recovery Plan: Your Bridge Over Troubled Waters," LAN Times, pp. 50-14:16, October 18, 1993.

20. Lamond, Bruce J, "An Auditing Approach to Disaster Recovery," Internal Auditor, pp. 38-47, October, 1990.

21. Lenckus, Dave, "Sun Trust's Disaster Plan Put to the Test - and Passed," Business Insurance, pp. 1-2, April 26, 1993.

22. Luecke, Randall W. and Cindy Hoopingarner. "Business Continuity Planning: The Hospital's Insurance Policy," Healthcare Financial Management, Vol. 47, No. 4, pp. 30-37, April, 1993.

23. Macoy, Ian W. "Beefed-up EDP Exams Near: Are You Ready?" ABA Banking 
Journal, pp. 32-33, May, 1992.

24. McManus, Alison, "Who's responsible for Planning?" Computing Canada, pp. 48-50, November 10, 1988.

26. Morris, Gordon F. "Securing Your Computer System With An EDP Audit," Corporate Controller, pp. 36-39,43, January/February 1992.

27. Muckian, Michael, "Beyond Compliance," Credit Union Magazine, pp. 4A-8A, December, 1994.

28. Negròn, Thomàs, "Audit Concerns in the Personal Computing Environment," Internal Auditing, pp. 38-43, Winter, 1992.

29. Perry, Lester, "The School Disaster Recovery Team," The Education Digest, pp. 27-29, May, 1990.

30. Phelps, Norma, "The Role of Top Management in Disaster Recovery Planning," Professional Safety, pp. 15-19, November, 1986.

31. Poker, Anna M., "Computer System Failure: Planning Disaster Recovery," Nursing Management, pp. 38-39, July, 1996.

32. Romei, Lura K., Patricia M Fernberg, and Mary S. Malik, "Disaster Recovery: Our Real Story," Managing Office Technology, pp. 24-25, January, 1995.

33. Romei, Lura K., Patricia M Fernberg, and Mary S. Malik, "Disaster Recovery: Are You Ready?" Managing Office Technology, pp. 26-28, January, 1995.

34. Sèguin, Marc, "Towards A Comprehensive Plan," Computing Canada, pp. 44,52, November 10, 1988.

35. van Collie, Shimon-Craig, "Disaster Planning," Banker's Monthly, pp. 38-39, 1993.

36. Vijayaraman, Bindiganavale S. and Hindupur V. Ramakrishna, "Disaster Preparedness of Small Businesses with MicroComputer Based Information Systems," Journal of systems Management, pp. 2832, June, 1993.

37. Wessellngh, Elleen S., "Standards of Care," Bank Administration, pp. 38-39, April, 1989.

38. Wong, Bo K., John A. Monaco, and Louise Sellaro, "Disaster Recovery Planning: Suggestions to Top Management and In- formation Systems Managers," Journal of Systems Management, pp. 28-33, May, 1994. 
